\title{
Designing Novel Nano-Immunoassays: Antibody Orientation vs Sensitivity
}

Puertas S. ${ }^{ \pm}$, Moros M. ${ }^{ \pm}$, Fernández-Pacheco R., Ibarra M.R., Grazú V.* and de la Fuente J.M.

Instituto de Nanociencia de Aragón (INA), Universidad de Zaragoza.

Campus Río Ebro, Edifício I+D, Mariano Esquillor, s/n, 50018 Zaragoza, SPAIN

E-mail:vgrazu@unizar.es,jmfuente@unizar.es

${ }^{ \pm}$These authors contributed equally to this work.

\begin{abstract}
There is a growing interest in the use of magnetic nanoparticles (MNPs) for their application in quantitative and highly-sensitive biosensors. The use of them as labels of biological recognition events and their detection by means of some magnetic method constitutes a very promising strategy for quantitative high-sensitive lateral-flow assays. In the present article, we report the importance of nanoparticle functionalization for the improvement of sensitivity for a lateral flow immunoassay. More precisely, we have found that immobilization of IgG anti-hCG through its polysaccharide moieties on magnetic nanoparticles allows more successful recognition of the hCG hormone.

Although we used the detection of hCG as a model in this work, the strategy of binding antibodies to MNPs through its sugar chains reported here is applicable to other antibodies. Its potential is huge as it will be very useful for the development of quantitative and high-sensitive lateral-flow assays for its use on human and veterinary, medicine, food and beverage manufacturing, pharmaceutical, medical biologics and personal care product production, environmental remediation, etc.
\end{abstract}

\section{INTRODUCTION}

Lateral-flow assays belong to a widespread methodology in biological recognition, their popularity arising from their simplicity, rapidity and affordable price. A very interesting characteristic of this kind of tests is that represent a well-established and very appropriate technology when applied to a wide variety of point-of-care (POC) or field use applications. Moreover, they can be used to analyze just about any biological sample including urine, tears, sweat, saliva, serum, plasma, whole blood, biopsied tissue and fluids [1]. Basically, they consist on a nitrocellulose membrane with micrometric pores allowing the flow of liquid via capillarity, where a biological recognition agent has been positioned in the test line and traps the targeted analyte if presents in the flowing liquid. Traditionally, lateral flow immunoassay (LFIA) tests are basically designed for colorimetric detection by visual inspection. Hereby, detection antibodies are usually labelled by coupling to colloidal gold, coloured latex microparticles, carbon, etc [2-3]. The test is considered positive when the amount of analyte is large enough so that the labelling colloidal particles can be detected by eye view (Scheme 1). 


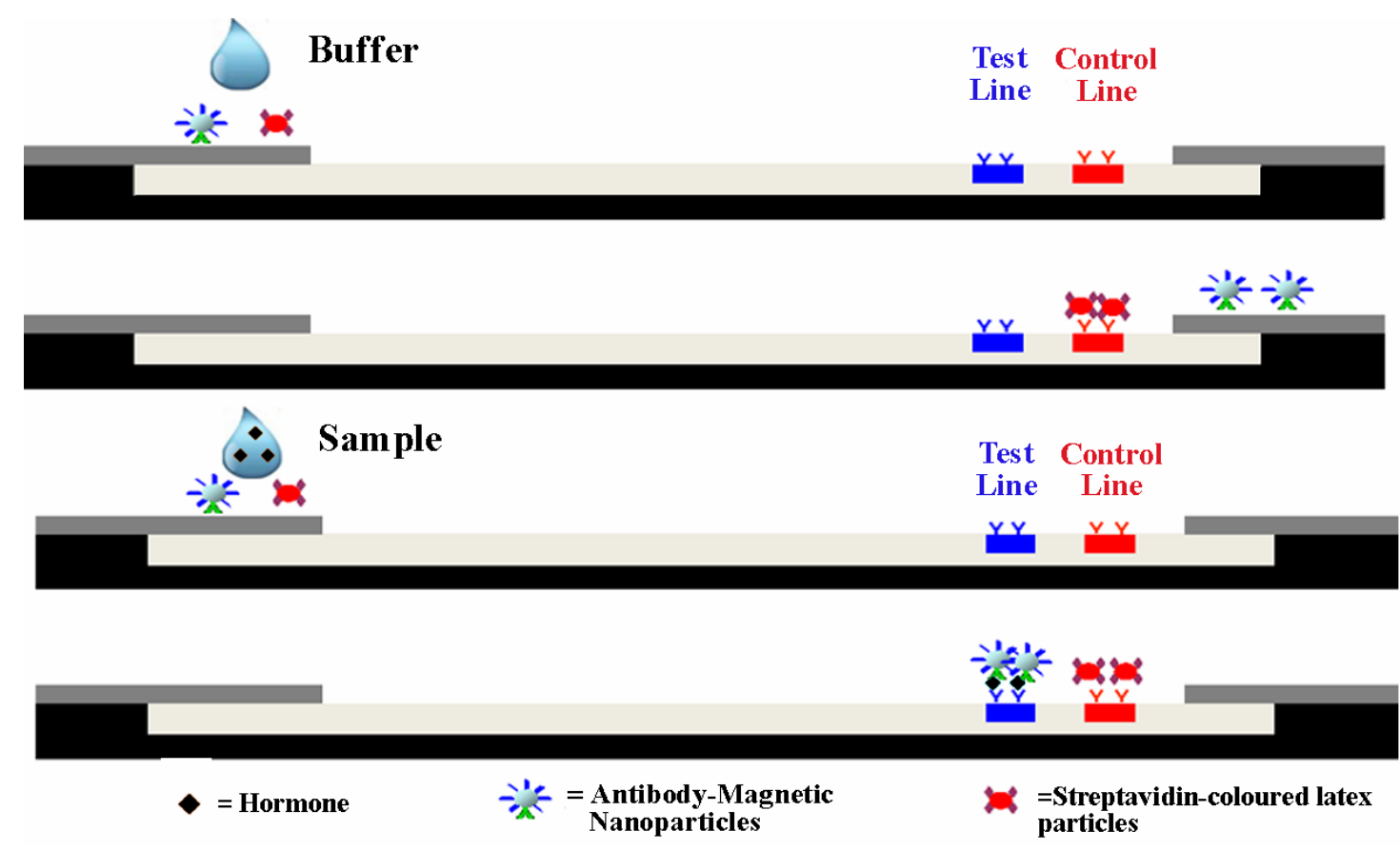

Scheme 1. Schematic diagram showing the lateral-flow assay for detection of hCG hormone. The specific binding of streptavidin-biotin was used as the control line (red line) in the membrane to assure the quality of the test. If the hormone is present in the sample, a specific binding with anti-hCG linked to the magnetic nanoparticle occurs (detection antibody). Only in this case, the magnetic nanoparticles are specifically captured in the test line (where another IgG clone that recognizes hCG hormone had been previously immobilized).

Negatively most tests using these labelling strategies suffer from low signal intensity and give only qualitative or semiquantitative results. One of the reasons of the relatively low sensitivity of LFIA tests compared to other immunoassay methods is that only signal coming from top layer $(10 \mu \mathrm{m})$ of the three-dimensional nitrocellulose membrane (usually hundred micrometers thick) can be detected, while the signal generated below is missed. Several strategies have been reported to increase their sensitivity such as using immunogold-silver staining to amplify the signal of colloidal gold, applying electrochemical detection, introducing an enzyme as the label, and so on [4-6]. However, these approaches usually require an additional operation handling step and thus makes lose the advantage of LFIA of being a rapid one-step assay.

Several reports have recently appeared in the literature addressing this problem. As a result, more quantitative LFIA assays are being developed based on fluorescent or electrochemical detection using quantum dots or electroactive nanomaterials (liposomes loaded with electroactive species, metallic nanoparticles, etc) [7-9]. In this line, magnetic nanoparticles (MNPs) are also a good alternative as quantitative signalling tags for developing magnetic LFIA tests. By the use of a magnetic reader, the magnetic signals coming from MNPs within the entire volume of the membrane can be detected $[1,10-12]$. This is a great advantage of MNPs over the use of other tags since nothing of the generated signal gets lost, improving the sensitivity of these tests between 10 to 1000 times [13]. In addition, magnetic signals generated by MNPs are not degraded over time, thus LFIA strips can be stored for rechecking whenever necessary. Magnetic immuno-cromatography testing had already been used to detect human papillomavirus, cardiac troponin I, cytokine interferon- $\gamma$, Escherichia soli and HIV antibodies [12, 14- 
17]. Moreover, it has been recently published how the size and magnetite content of MNPs could affect magnetic LFIA performance [13]. However, to our knowledge, less is known about whether the method used to link the antibody to the MNPs would affect this test performance.

It has been extensively reported with other immunoassay tests formats that the use of adequate immobilization strategies, in order to orient correctly the antibody $(\mathrm{Ab})$, could strongly affect the achieved sensitivity [18-24]. Hereby, among different strategies commonly used, covalent binding presents advantages such as increasing antibody stability and ensuring the protein binding sites availability. However, a noncorrect orientation of the antibody may lead to a complete loss of the biological activity of the antibody due to the blocking of the protein binding sites by the support.

Here, we compare the sensitivity achieved in lateral flow-based immunoassay tests using two different methods for the covalent immobilization of antibodies on magnetic nanoparticles. The first strategy used is the conventional procedure using antibody amino groups and forming an amide bond with carboxylic groups from the nanoparticles. The second method consists on the use of the polysaccharidic region located in the Fc region of the antibody and the use of aminated nanoparticles. To our knowledge, few contributions in this line can be found on literature with magnetic microbeads and still less with magnetic nanoparticles [25-32]. The biofunctionalization of magnetic nanoparticles suffers some limitations when compared to surfaces and microbeads, such as easy aggregation with small changes of $\mathrm{pH}$ and/or ionic strength, polymeric shell instability, batch to batch MNPs irreproducibility, or presence of surfactants. Though it is true that the analytical performance of the lateral flow immunoassay tests can be affected by a wide range of different parameters (type and pore size of the membrane, type of absorbent and the colloidal stability of the nanoparticles among others), the results obtained here showed that also the selected methodology to covalently attach the antibody to the MNP could affect.

\section{MATERIALS}

Carboxylated magnetic nanoparticles (MNPs-COOH) were supplied by Estapor (Merck Co, France; Batch numbers: R06-26 lot 7599). Aminated magnetic nanoparticles $\left(\mathrm{MNPs}-\mathrm{NH}_{2}\right)$ were also from Estapor (Batch number: R04-11 lot 7418). Monoclonal antibodies anti-hCG (clone 5014 and 5016) were from Medix Biochemica (Kauniainen, Finland). Sodium cyanoborohydride $\left(\mathrm{NaCNBH}_{3}\right)$, N-hydroxysuccinimide (NHS) N-(3dimethylamino propyl)-N'-ethylcarbodiimide hydrochloride (EDC), tris(hidroxymethil) aminomethane (TRIS), ethanolamine, ethilendiamine, amino-polyethylene glycol (750 or $5000 \mathrm{Da}$ ), sodium periodate $\left(\mathrm{NaIO}_{4}\right)$, and human chorionic gonadotropin (hCG) hormone was bought to Sigma-Aldrich (St. Louis, MO, USA). Coomasie (Bradford) protein assay kit and bovine serum albumin (BSA) as protein standard were bought from Thermo Scientific (Rockford, IL, USA). Sephadex G-25 gel filtration columns were from GE Healthcare Life Sciences. Nitrocellulose strips, where the anti-hCG IgG clone 5014 was previously immobilized in the test line, was kindly donated by CertestBiotec (Zaragoza, Spain). Buffers were prepared according to standard laboratory procedure. Other chemicals were reagent grade and used as received. 


\section{METHODS}

\section{Functionalization of magnetic nanoparticles with anti-hCG antibody}

Srtategy 1: Immobilization via the more reactive amine groups of the antibody (Random immobilization). 10mg of MNPs-COOH were washed several times with $1 \mathrm{~mL}$ of $10 \mathrm{mM}$ MES pH 6.1. Then, they were incubated for $30 \mathrm{~min}$ at $37^{\circ} \mathrm{C}$ with $1 \mathrm{~mL}$ of $10 \mathrm{mM}$ MES pH 6.0 containing $5 \mu \mathrm{mol}$ of EDC and $7.5 \mu \mathrm{mol}$ of NHS. After that, they were washed three times in the same buffer and were incubated during $2 \mathrm{~h}$ at $37^{\circ} \mathrm{C}$ with $1 \mathrm{~mL}$ of a $100 \mu \mathrm{g} / \mathrm{mL}$ antibody solution prepared in $10 \mathrm{mM}$ MES pH $7.0300 \mathrm{mM} \mathrm{NaCl}$. Finally, the MNPs were washed several times with 10mM MES pH 6.0.

Strategy 2: Immobilization via the polysaccharidic region of the antibody (Oriented immobilization). $1 \mathrm{~mL}$ of an antibody solution $1 \mathrm{mg} / \mathrm{mL}$ in $10 \mathrm{mM}$ sodium phosphate $\mathrm{pH}$ 7.0 was incubated with $100 \mu \mathrm{L}$ of $0.1 \mathrm{M} \mathrm{NaIO}_{4}$ (solubilised in water) during $2 \mathrm{~h}$ at $4^{\circ} \mathrm{C}$ and preserved from light. Then, the oxidized antibody was purified by Sephadex G-25 gel filtration column with $10 \mathrm{mM}$ sodium phosphate $\mathrm{pH}$ 8.0. Aliquots of $10 \mathrm{mg}$ of MNPs$\mathrm{NH}_{2}$ were incubated during $2 \mathrm{~h}$ at $37^{\circ} \mathrm{C}$ with $1 \mathrm{~mL}$ a $100 \mu \mathrm{g} / \mathrm{mL}$ solution of oxidized antibody in $10 \mathrm{mM}$ sodium phosphate $\mathrm{pH} 8.0$. The functionalized nanoparticles were washed three times with 10mM MES pH 6.0.

The Schiff bases formed among the amine groups of the MNPs and the aldehyde groups of the oxidized $\mathrm{Ab}$ were reduced by incubation with sodium cyanoborohydride. Aliquots of $10 \mathrm{mg}$ of MNPs-NH $\mathrm{N}_{2}$ were incubated with $1 \mathrm{~mL}$ of different concentrations of $\mathrm{NaCNBH}_{3}$ solution $(0.05-1 \mathrm{M})$ prepared in $10 \mathrm{mM}$ sodium phosphate $\mathrm{pH} 8.0$. After $30 \mathrm{~min}$ at $37^{\circ} \mathrm{C}$, the reduced nanoparticles were washed three times with $10 \mathrm{mM}$ sodium phosphate $\mathrm{pH}$ 8.0. To check the reduction of the Schiff bases and therefore the irreversible binding of the antibodies, $1 \mathrm{mg}$ of the IgG functionalized MNPs was suspended in $100 \mu \mathrm{L}$ of elution solution containing $0.5 \mathrm{M}$ of TRIS in sodium phosphate $\mathrm{pH}$ 8.0. The mixture was gently stirred at $25^{\circ} \mathrm{C}$ for 30 minutes.

The antibody conjugation efficiency was determined using the Bradford protein concentration assay for both immobilization strategies [33]. To determine the protein concentration of all the samples, a calibration curve was made using BSA as protein standard. The range of linearity of the assay was from $5 \mu \mathrm{g} / \mathrm{mL}$ to $250 \mu \mathrm{g} / \mathrm{mL}$. The MNPs after being conjugated with antibody were collected with a magnet. The supernatant was then centrifuged at $12,000 \mathrm{~g}$ for $5 \mathrm{~min}$ to remove any remaining MNPs. A reference solution was prepared having exactly the initial antibody concentration at the same conditions ( $\mathrm{pH}$, ionic strength). Therefore, the decrease in protein concentration in the supernatant can be directly correlated to the amount of the antibody immobilized on the MNPs (mg Ab/mg MNPs). As incubations were carried out with $10 \mathrm{mg}$ of the each MNP type and $1 \mathrm{~mL}$ containing $100 \mu \mathrm{g} / \mathrm{mL}$ of $\mathrm{Ab}$, protein determinations of all the samples fall within the $95 \%$ confidence interval of the Bradford Assay used. Besides, all measurements were carried out at least in triplicate, and standard errors were never over 5\%. Immobilization efficiency yield was defined as: [(initial concentration of protein - protein concentration after immobilization)/initial concentration of protein] $\times 100$.

The same approach was used to determine the degree of irreversible binding via the polysaccharidic moieties of the Ab. The amount of protein of the supernatants obtained after incubating the $\mathrm{Ab}$ functionalized MNPs with TRIS was also determined by Bradford assay. Desorption yield was defined as: [(desorbed $\mu \mathrm{g} \mathrm{Ab} / \mathrm{mg}$ of MNPs)/(immobilized $\mu \mathrm{g}$ of Ab/mg of MNPs)]x100. 
Incubations using non activated $\mathrm{COOH}$ MNPs and non oxidized $\mathrm{Ab}$ were also carried out as controls in order to determine unspecific Ab binding ratio for Strategy 1 and 2 respectively.

\section{SDS-PAGE analysis}

Samples of the different soluble and immobilized antibody preparations were analyzed by SDS-PAGE [34]. In the case of immobilized preparations, the antibodyfunctionalized MNPs were boiled in the presence of $20 \%$ SDS and $10 \%$ mercaptoethanol for $10 \mathrm{~min}$, and the obtained supernatants were used for the SDSPAGE analysis. This treatment releases any antibody chain that is not irreversible bound to the MNPs [35].

SDS-PAGE was performed using Phast System (Amersham Pharmacia Biotech) apparatus, following the standard procedure. Gradient gels (8-15\%) were used. Gels were stained with Coomasie brilliant blue (R250).

\section{Inertization of the final nanoparticles surface}

In the case of MNP-COOH, aliquots of $10 \mathrm{mg}$ of $\mathrm{Ab}$ functionalized MNPs were incubated with $1 \mathrm{~mL}$ of $10 \mathrm{mM}$ MES pH 6.0 containing different amounts (0.1-100 mM) of amino containing compounds (TRIS, imidazol, etanolamine, aminopolyethilenglicol) or $1 \%(\mathrm{w} / \mathrm{v})$ of BSA. In the case of $\mathrm{MNP}-\mathrm{NH}_{2}$, aliquots of $10 \mathrm{mg}$ of nanoparticles were incubated during $16 \mathrm{~h}$ at $24^{\circ} \mathrm{C}$ with $1 \mathrm{~mL}$ of $1 \%(\mathrm{w} / \mathrm{v})$ BSA solution prepared in $10 \mathrm{mM}$ sodium phosphate $\mathrm{pH} 8.0$.

For both kinds of MNPS, after $16 \mathrm{~h}$ of incubation at $24^{\circ} \mathrm{C}$ all the blocked MNPs were extensively washed with 50mM MES pH 7.0 and stored at $4^{\circ} \mathrm{C}$ until use.

\section{Biological activity of the antibody functionalized nanoparticles.}

One end of the nitrocellulose strips, where the anti-hCG IgG clone 5014 was previously immobilized in the test line, were immersed in solutions containing $5 \mu \mathrm{L}$ of a suspension $1 \%(\mathrm{w} / \mathrm{v})$ of each nanoparticle-antibody conjugate and $40 \mu \mathrm{L}$ of running buffer composed by: sodium phosphate $10 \mathrm{mM}, 150 \mathrm{mM} \mathrm{NaCl}, 0.3 \%$ (w/v) BSA, $0.1 \%$ (v/v) Tween-20 at pH 7.4 and different amounts of hCG hormone (0.1-100 mUI/mL). Elution flow proceed by capillarity and within a few minutes time capture of IgGparticle conjugates produce the appearance of a brownish band in the test line. The intensity of the colour is related with the amount of trapped nanoparticles. The simultaneous presence of a green band in the control line assure the quality of the test, which is based in the specific binding of coloured latex particles containing streptavidin to the control line where biotin was previously immobilized. The experiments were carried out at least three times. The concentration of hCG used is expressed in international units (IU) per $\mathrm{mL}$. By definition $1 \mathrm{IU}$ of $\mathrm{hCG}$ is equal to $0.11 \mu \mathrm{g}$ of hormone $(\sim 3.0 \mathrm{pmol})[36]$.

\section{RESULTS AND DISCUSSION}

\section{Functionalization of MNPs with antibodies}

The immobilization of biologically active molecules requires good steric accessibility to active binding sites [18]. This is a more difficult task when the biomolecules to link are asymmetrical (e.g.: antibodies). In order to avoid losing antigen binding capacity, it is preferred that the antigen-binding sites (the two Fab domains) of 
the antibody be oriented upward and away from the surface of the nanoparticle. In the present study two different strategies for covalently binding anti hCG-IgG are compared: $i)$ through the more reactive amino group of the antibody, and ii) via its polysaccharide residues.

The first strategy used is the most extended protocol for the conjugation of Abs to supports in the literature. It is based on the reaction of carboxyl groups of nanoparticles with amino groups of the antibody molecule. To achieve this covalent reaction it is necessary first to activate the carboxyl groups with EDC and NHS. As it can be observed in Figure 1, only when the carboxyl groups of the nanoparticles are activated the antibody becomes attached to the MNPs surface.

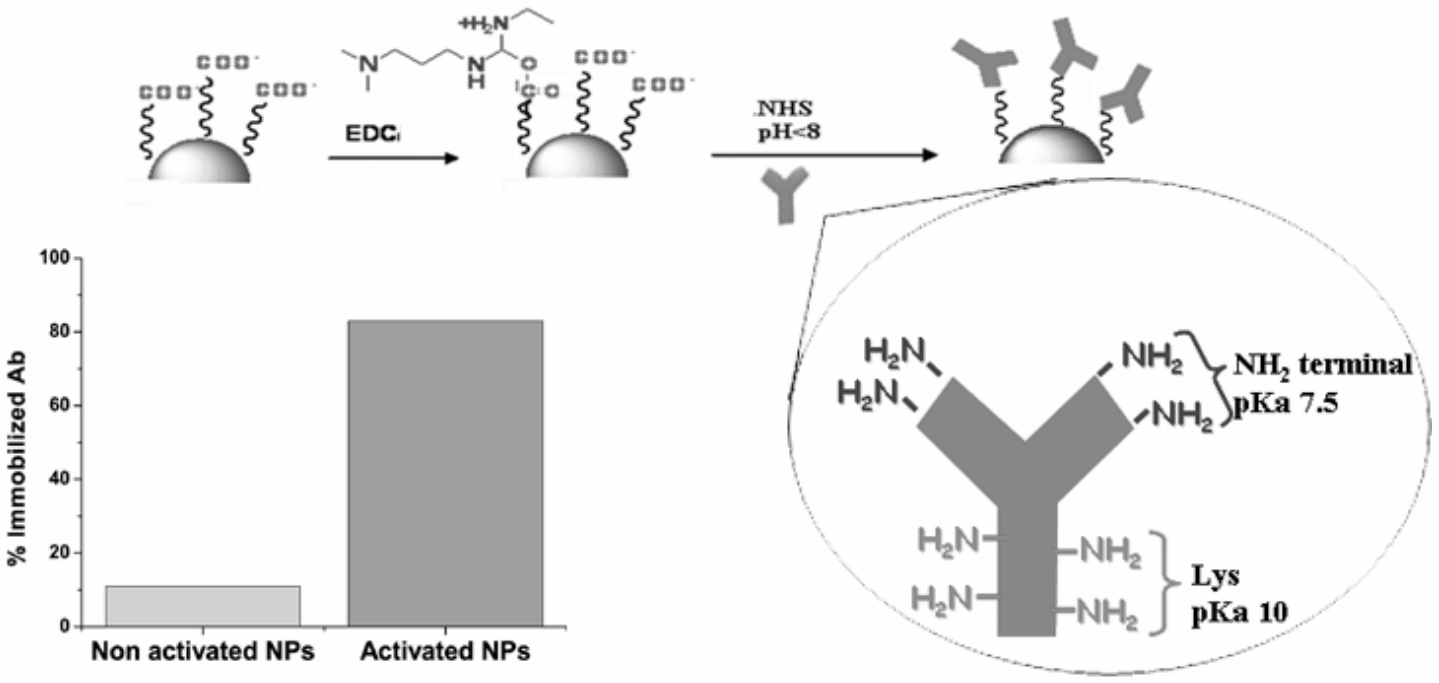

Figure 1. Yield of covalent immobilization of anti-hCG through its more reactive amino groups. The immobilization was performed with both EDC-NHS activated and non activated MNPs-COOH.

The second strategy used consists on the covalent attachment via the polysaccharide moieties of the antibody. This requires first the oxidation of the carbohydrates with periodate to generate aldehyde groups which can react with amino groups present in the nanoparticle surface. The Schiff bases resulting from the aminealdehyde reaction can be stabilized by its reduction with sodium cyanoborohydride. In this way, the antibody remains attached to the MNPs in an irreversible way by means of very stable secondary amino bonds.

To guarantee a correct reduction of the Schiff bases formed by this process, the functionalized MNPs were incubated with TRIS for 30 minutes and then the amount of desorbed protein was analyzed by determining the protein concentration of the supernatants. If the Schiff bases are not rightly reduced, the immobilized proteins should be eluted by addition of compounds with low $\mathrm{pK}$ amino groups, such as TRIS [37]. Figure 2 shows that the percentage of released protein from the NPs decreased whereas the concentration of $\mathrm{NaCNBH}_{3}$ increased, and $0.25 \mathrm{M}$ of $\mathrm{NaCNBH}_{3}$ was enough to guarantee the stable covalent bonding of the $\mathrm{Ab}$. 


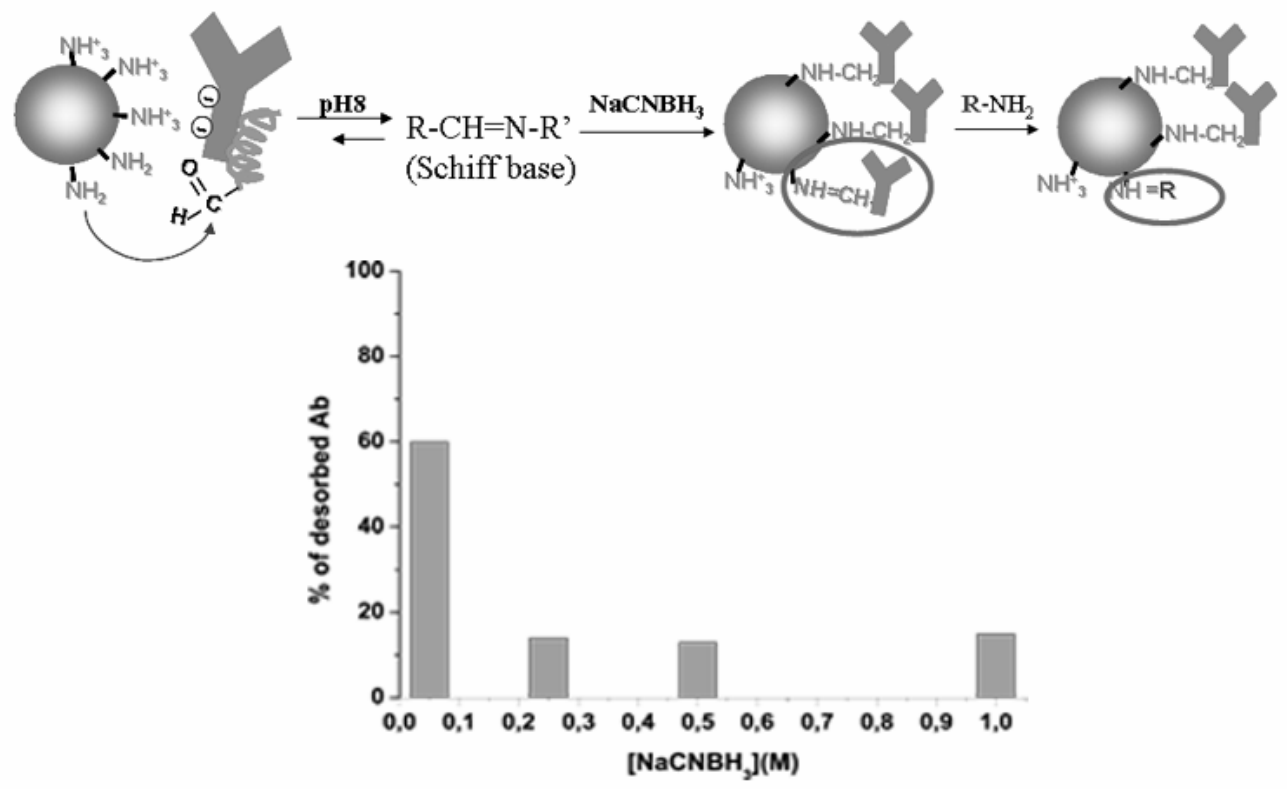

Figure 2. Effect of the concentration of $\mathrm{NaCNBH}_{3}$ in the degree of irreversible binding of the Ab, achived via its oxidized polisaccharidic moieties. The figure shows percentages of $\mathrm{Ab}$ desorbed from the MNPs with TRIS after reduction with different amounts of $\mathrm{NaCNBH}_{3}$. Desorption yield was defined as: (desorbed $\mu \mathrm{g} \mathrm{Ab} / \mathrm{mg}$ of MNPs)/(immobilized $\mu \mathrm{g}$ of Ab/mg of MNPs).

It is important to point out that the amount of anti-hCG immobilized was determined by quantifying the difference in protein concentration in the supernatant before and after immobilization, using the Bradford protein concentration assay [33]. With both immobilization procedures the final amount of antibody covalently link to the NPs was similar $\left(0.4 \mathrm{mg} / \mathrm{m}^{2}\right)$.

\section{Inertization of the final nanoparticle surface}

After immobilizing the antibody in a covalent manner, the obtained nanoparticle surface should be chemical and physically inert to prevent unspecific adsorptions of other components of the sample. Otherwise, the sensitivity of the system may be drastically reduced. In addition, in the case of lateral flow assays, it is also necessary to avoid any unspecific interactions between the magnetic nanoparticles and the nitrocellulose membrane (which would imply that MNPs could not flow along the strip), or the test line (that will imply a false positive result). As it could be observed on Figure 3, MNPs without a correct inertization could interact and get retained on the test line even in the absence of the analyte (hCG hormone). To avoid this fact, and guarantee the right passivation of the MNPs, different blocking agents have been used: ethanolamine, TRIS, imidazol, bovine serum albumin (BSA), amino-polyethyleneglycol of different sizes ( 750 or $5000 \mathrm{Da}$ ). The best results were obtained with BSA in the case of MNP-NH , and with BSA or PEG of $5000 \mathrm{Da}$ in the case of the MNP-COOH. 


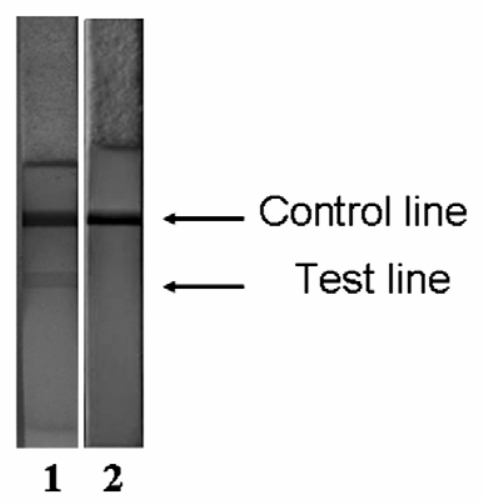

\section{Non passivated}

\section{Passivated}

Figure 3. Importance of the inertization step after covalent binding of the Ab. MNPs$\mathrm{COOH}$ without inertization interacts with the test line in the absence of hCG (false positive results). This was solved by blocking the remaining $\mathrm{COOH}$ groups with BSA. Similar results were obtained with $\mathrm{MNPs}-\mathrm{NH}_{2}$.

\section{Biological activity of the antibody functionalized nanoparticles.}

The antigen recognition capacity of all the $\mathrm{Ab}$ functionalized MNPs obtained using both immobilization strategies (via the antibody amino or sugar groups) was evaluated using a lateral-flow assay for detection of pregnancy hormone. This is one of the most popular and standardized immunochromatographic assay in which the human chorionic gonadotropin hormone (hCG) produced during pregnancy is the targeted analyte. The test consists in the specific attachment of hCG hormone to the anti-IgG (clone 5016) immobilized on the nanoparticles and the subsequent detection in a nitrocellulose membrane strip where other monoclonal IgG (clone 5014), also specifically for hCG hormone, was previously immobilized in the test line (Scheme 1).

Figure 4 clearly shows that the sensitivity achieved has been clearly improved when the $\mathrm{Ab}$ was linked to the nanoparticles via its polysaccharidic chains. A concentration of hCG hormone of $6 \mathrm{mIU} / \mathrm{mL}$ could be detected by eye view using this immobilization strategy. However, this hormone concentration could not be detected using MNPs in witch the antibody was immobilized via its amino groups. It must be highlighted that the protein content per MNP $\mathrm{m}^{2}$ is the same for both kind of MNPs $(0.4$ $\mathrm{mg} / \mathrm{m}^{2}$ ). Moreover, a control assay in the absence of analyte has been carried out ensuring the absence of unspecific interactions between the MNPs and the test line. 


\section{a)Anti-hCG linked through sugar chains}

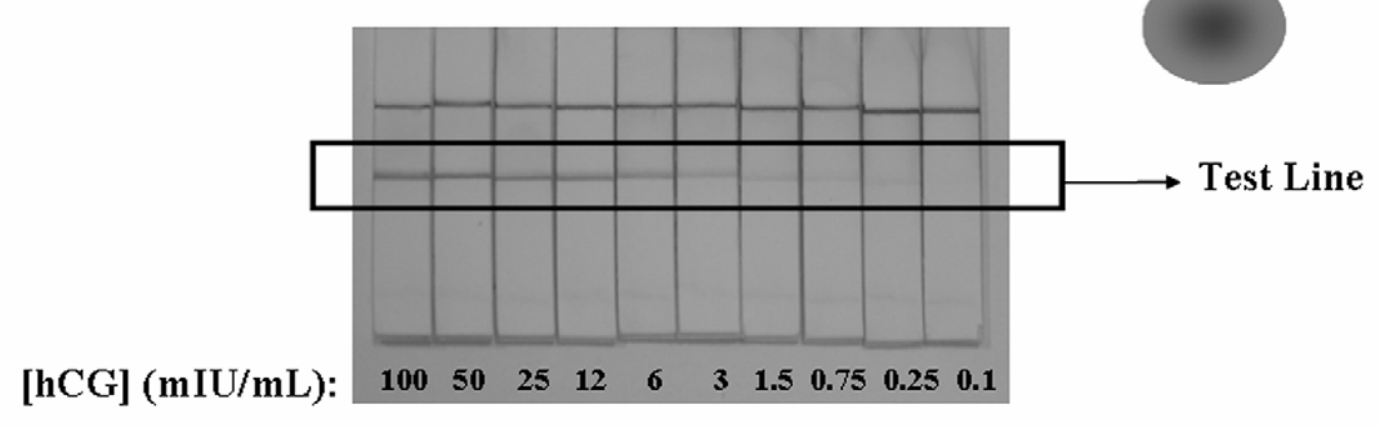

\section{b)Anti-hCG linked through amino moieties}
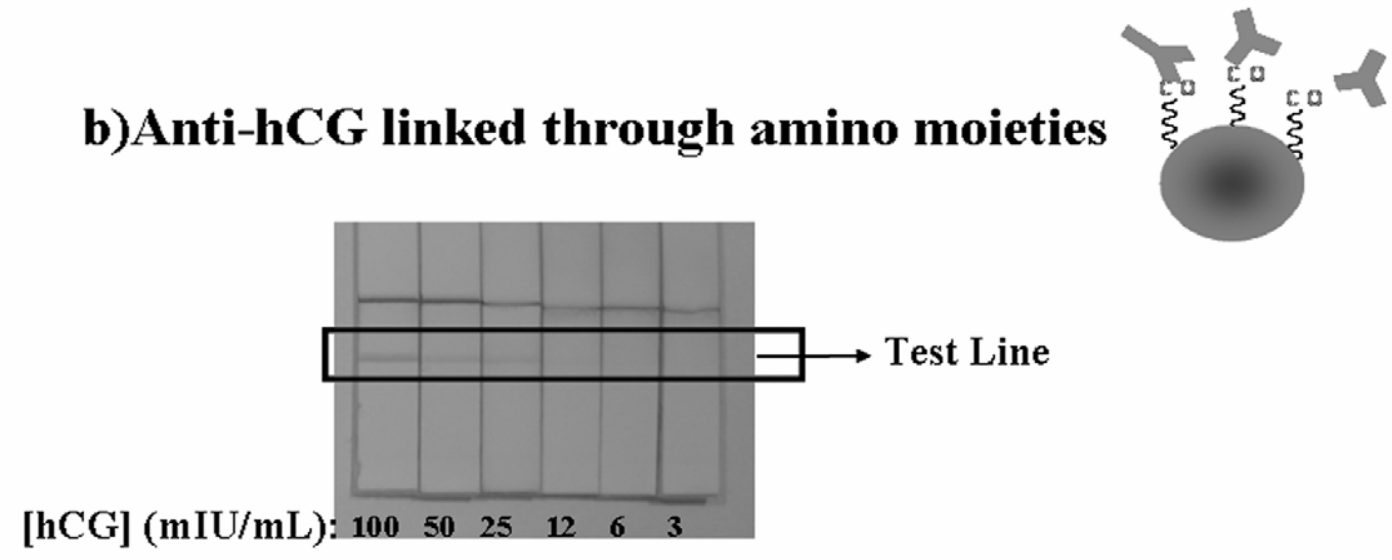

Figure 4. Pictures of the immunomagnetic lateral-flow assay strips obtained using different hCG hormone concentrations. In a) magnetic nanoparticles with anti-hCG linked through its sugar chains where used. In b) the IgG was attached to the surface of magnetic nanoparticles via its amino moieties. The concentration of hCG used are expressed in international units $\times 10^{-3}(\mathrm{mIU})$ per $\mathrm{mL}$. By definition $1 \mathrm{IU}$ of hCG is equal to $0.11 \mu \mathrm{g}$ of hormone $(\sim 3.0 \mathrm{pmol})$.

The analytical performance of the lateral flow immunoassay tests can be affected by a wide range of different parameters. In spite of the fact that both types of MNPs used (carboxilated and aminated) have the same size $(200 \mathrm{~nm})$, the obtained results might be a consequence of differences in colloidal stability among them. However, we think that in our case this effect is minimized as a final inertization step with the same blocking agent (BSA) was performed with both immobilization strategies. Therefore, we think that another fact that could also be responsible of the difference in sensitivity observed is a different final orientation of the antibodies on the MNP surface.

Clearly, the orientation of the antibodies immobilized via its amino groups seems less adequate. To explain that, it is necessary to point out that amino moieties are ionizable groups and that covalent reaction between amine groups of the $\mathrm{Ab}$ and activated carboxyl groups of the MNPs could only occurs if amino moieties are deprotonated (that means working at a $\mathrm{pH}$ value above its $\mathrm{pK}$ ). In an antibody molecule, it is possible to distinguish at least two types of amino groups exposed to the medium: $i$ ) the terminal amino groups, and ii) the $\varepsilon$-amino moiety of lysine residues (the most abundant ones). Both kinds of amino groups have different ionization behaviours 
depending of $\mathrm{pH}$. While amino terminal groups have a $\mathrm{pK}$ around $7-8$, $\varepsilon$-amino groups of Lys residues have a $\mathrm{pK}$ close to 10 . As the $\mathrm{Ab}$ attachment must be done at $\mathrm{pH}$ values less than 8.0 (due to instability of the EDC/NHS activated carboxyl groups at higher $\mathrm{pH}$ values), the $\mathrm{Ab}$ amino terminal groups are the most reactive at these reaction conditions. As antibodies are formed by four polypeptide chains, they contain four amino terminal moieties, and all of them located in the Fab region where antigen recognition takes place (Figure 5a). This fact implies a random antibody orientation on the MNPs surface, which could contribute to the lower sensitivity obtained with this functionalization strategy as one or both of the antigen binding sites may be positionated in such a way that the binding of the antigen is sterically hindered [25,38, 39]. Conversely, the antigen binding capacity when antibodies where immobilized through its oxidized sugar chains was clearly better. This should be a consequence of a proper $\mathrm{Ab}$ orientation, as it is well established that all IgG class antibodies have one conserved N-glycosylation site at Asn-297 in the $\mathrm{C}_{\mathrm{H}} 2$ domain of the Fc region of each heavy chain (Figure 5b) [40]. Therefore, binding the Ab through its carbohydrate moieties assures the coupling of the $\mathrm{Ab}$ through a site far removed from the antigen binding sites. This allow directing the binding regions of the Ab upward and away from the MNP surface and could also contributed to the better sensitivity obtained as a consequence of a highest retention of the antigen binding capacity [18,25,41-43].

a)

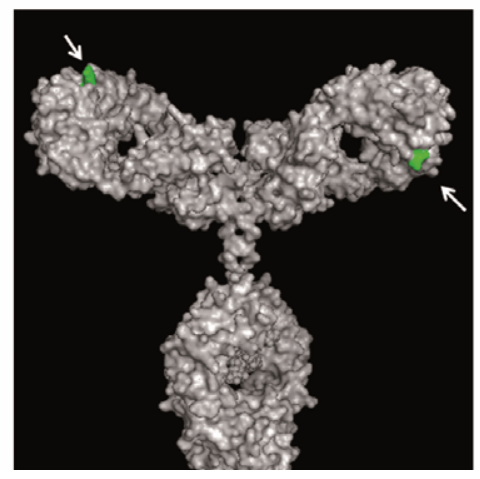

b)

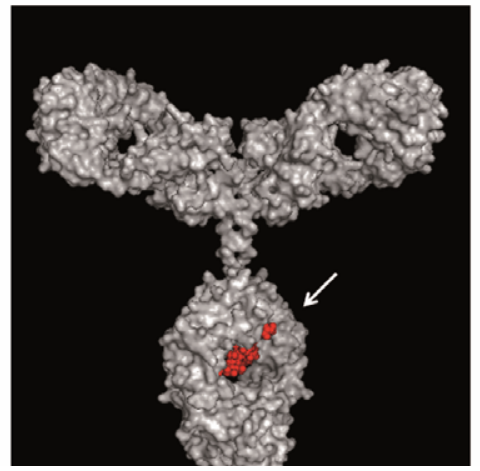

Figure 5. 3D structure of $\mathrm{Ig} G$ from rabbit (Anti-HRP). The structure was obtained from the Protein Data Bank (PDB) and visualized using PyMol v0.99. The PDB entry for the antibody was 1IGY. a) location of the amino terminal groups (in purple). a) location of the antibody sugar moieties (in orange).

A complementary analysis, based in the dissimilarity of molecular weight among the $\mathrm{Ab}$ polypeptide chains, was performed in order to check differences in the $\mathrm{Ab}$ orientation among both immobilization strategies. The obtained antibody-functionalized MNPs were boiled in the presence of SDS and mercaptoethanol. This treatment releases any antibody chain that is not irreversible bound to the MNPs [35]. Each antibody molecule consists of four polypeptides, two heavy chains $(50 \mathrm{kDa})$ and two light chains $(25 \mathrm{kDa})$, joined by disulfide bridges to form a "Y" shaped molecule. When subjected to SDS-PAGE, each antibody molecule is split into heavy and light chain fragments and thus should give two bands (one at approx $50 \mathrm{kDa}$ and another at approx $25 \mathrm{kDa}$ ) upon SDS-PAGE analysis. When immobilization is done with a site-selective orientation via the $\mathrm{Ab}$ sugar moieties, only the heavy chain fragments should be irreversible attached to the MNP. Therefore, when MNPs are boiled with SDS and mercaptoethanol only the light chains of the $\mathrm{Ab}$ could be released. In the case of randomly immobilized $\mathrm{Ab}$, both 
light and heavy chains could be released by this treatment (Figure 6). The electrophoretic pattern obtained confirms a different $\mathrm{Ab}$ orientation for each immobilization strategy.

a)

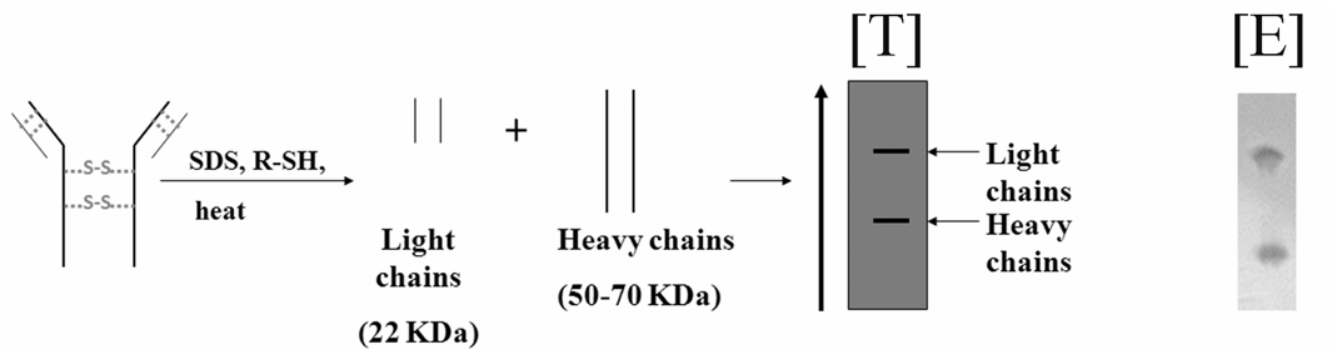

b)
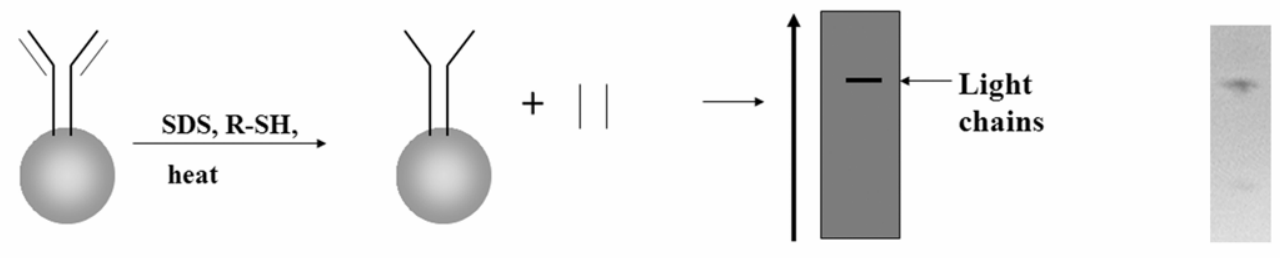

c)
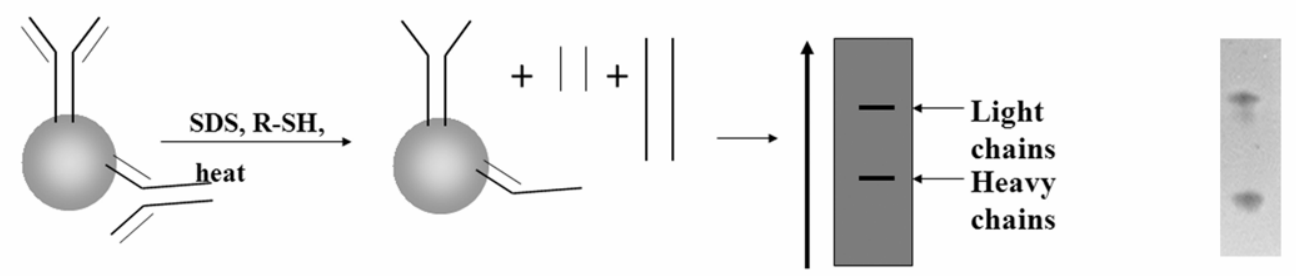

Figure 6. SDS-PAGE analysis of the supernatant obtained after boiling Abfunctionalized MNPs in the presence of SDS and mercaptoethanol. [T]= expected theorical electrophoretic pattern. $[\mathbf{E}]=$ obtained experimental electrophoretic pattern. a) Soluble antibody. Antibodies immobilized via its b) carbohydrate chains or c) amine moieties.

\section{CONCLUSION}

In the present manuscript we show the importance of using an adequate immobilization strategy to obtain highly-sensitive detection with immunochromatographic lateral-flow assays. We have verified that binding the Ab through its polysaccharidic moieties, clearly improved the biological recognition capacity over the IgG-nanoparticles functionalized via attachment through the antibody more reactive amino groups. The sensitivity of the test has been increased in one order of magnitude when the antibody is correctly oriented. Additionally, we have also shown the importance of obtaining a fully inert MNPs surface after antibody binding. 
In this work we used the detection of human chorionic gonadotropin (hCG) as a model, as it is a very well known and established test in the clinical market. However, the strategy of binding Abs to MNPs through its sugar chains reported here could be applied to others antibodies of interest for areas as diverse as environmental remediation, agriculture, veterinary, biowarfare, food, clinical diagnostics, therapeutic monitoring, and industrial testing as well as newer areas such as proteomics and theragnostics.

\section{AKNOWLEDGMENTS}

Financial support by the Spanish Ministry of Science (through projects NAN200409270-CO3-03, PROFIT CIT 010000-2007-27, CTQ 2008-03739 and CONSOLIDER NANOBIOMED), is acknowledged. S Puertas thanks DGA for a fellowship and JM de la Fuente thanks ARAID for financial support. Authors thank to Iñigo Echaniz for technical support. The authors would also like to thank other BioNanoSurf members and Dr. F. Luvi for their contributions to the paper. Fruitful discussions with Dr. C. Génzor and B. Velasco are also acknowledged.

\section{REFERENCES}

[1] O'Farrell B and Chun P and Faulstich K, Gruler R, Eberhard M, Lentzch D, Haberstroh K Lateral Flow Immunoassay ed R C Wong and $\mathrm{H}$ Y Tse (New York: Humana Press) p 1, 75, 157.

[2] Warsinke A 2009 Anal Bioanal Chem 393 1393-1405.

[3] Peruski A H, Peruski Jr L.F 2003 Clin. Diagn. Lab. Immunol. 10 506-513.

[4] Kim H-S, Ko H, Kang M-J, Pyun J-P 2010 BioChip J. 4(2) 155-160.

[5] Choi D H, Lee SK, Oh Y K, Bae B W, Lee S D, Kim S, Shin Y-B, Kim M-G Biosens Bioelectron 201025 1999-2002

[6] G.A. Posthuma-Trumpie, J. Korf, A. van Amerongen 2009 Anal. Bioanal. Chem. 393, 569-582.

[7] Zou Z, Du D, Wang J, Smith JN, Timchalk C, Li Y, Lin Y 2010 Anal Chem 84 $5125-5133$.

[8] Tang D, Sauceda JC, Lin Z, Ott S, Basova E, Goryacheva I, Biselli S, Lin J, Niessner R, Knopp D 2009 Biosens Biolelectron 25(2) 514-518.

[9] Xia XH, Xu Y, Zhao XL, Li QG 2009 Clin Chem 55(1) 179-182.

[10] LaBorde RT and O'Farrell B 2002 IVD Technology 8(3) 36-41.

[11] MagnaBioSciences LLC, "Application Note for the Magnetic ImmunoChromatographic Test (MICT)"; available from Internet: http://www.magnabiosciences.com/ technology.html

[12] Taton K, Johnson D, Guire P, Lange E, Tondra M 2009 J Magn Magn Mater 321 1679-1682.

[13] Wang Y, Xu H, Wei M, Gu H, Xu Q and Zhu W 2009 Mat. Sci. Eng. C-Bio. S 29(3) 714-718.

[14] Peck R B, Schweizer J, Weigl BH, Somoza C, Silver J, Sellors J W, Lu P S 2006 Clin Chem 52 2170-2172.

[15] Xu Q, Xu H, Gu H, Li J, Wang Y, Wei M 2009 Mat. Sci. Eng. C-Bio. 29 702-707.

[16] Flanagan RJ, Martinez G 2010 J AOAC Int 93(3) 922-927.

[17] Granade TC, Workman S, Wells SK, Holder AN, Owen SM, Pau C-P 2010 Clin Vaccine Immunol 17(6) 1034-1039.

[18] Turková J 1999 J. Chromatogr. B 722, 11-31. 
[19] Nisnevitch M and Firer M 2001 J. Biochem Biophys Methods 49 467-480.

[20] Jung Y, Jeong JY, Chung BH 2008 Analyst 133 697-701.

[21] Derwinska K, Sauer U, Preininger C 2008 Talanta 77 652-658.

[22] Lo YS, Nam DH, So HM, Chang H, Kim JJ, Kim YH, Lee JO 2009 ACS Nano 3(11) 3649-3655.

[23] Kim S, Pyo H-B, Ko S H, Ah C S, Kim A, Kim W-J 2010 Langmuir 26(10) 7355 7364.

[24] Liu F, Dubey M, Takahashi H, Castner D G, Grainger D W 2010 Anal Chem 82 2947-2958.

[25] Fuentes M, Mateo C, Guisan J M and Fernandez-Lafuente R 2005 Biosens. Bioelectron. 20(7) 1380-1387.

[26] Jaffrezic-Renault N, Martelet C, Chevolot Y and Cloarec J P 2007 Sensors 7 589614.

[27] Roque ACA, Bispo S, Pinheiro ARN, Antunes JMA, Goncalves D, Ferreira HA 2009 J Mol Recognit 22(2) 77-82.

[28] Lin P-C, C S-H, Wang K-Y, Chen M-L, Adak AK, H J-R R, Chen Y-J, Lin C-C 2009 Anal Chem 81 8774-8782.

[29] Zhuang J, Cheng T, Gao L, Luo Y, Ren Q, Lu D, Tang F, Ren X, Yang D, Feng J, Zhu J,Yan X 2010 Toxicon 55(1) 145-152.

[30] Liu RP, Liu JT, Xie L, Wang MX, Luo JP, Cai XX 2010 Talanta 81(3)1016-1021.

[31] Tang D, Sauceda J C, Lin Z, Otta S, Basova E, Goryacheva I, Biselli S, Lin J, Niessnera R and Knopp D 2009 Biosens. Bioelectron. 25(2) 514-518.

[32] Dittmer W U, Evers T H, Hardeman W M, Huijnen W, Kamps E, de Kievit P, Neijzen J H M, Nieuwenhuis J H, Sijbers M I J, Dekkers D W C, Hefti M H and Martebs M F W C 2010 Clin. Chim. Acta, 411(11-12) 868-873..

[33] Bradford M. 1976 Anal. Biochem. 72 248-254.

[34] Laemmli, U. K.1970 Nature 227 680-685.

[35] Bastida A, Sabuquillo P, Armisen P, Fernandez-Lafuente R, Huguet J, Guisan JM. 1998 Biotechnol Bioeng 58486 -493.

[36] Storning P L, Glaines-Das R E and Bangham D R 1980 Endocrinology 84 295310.

[37] Grazu V, Betancor L, Montes T, Lopez-Gallego F, Guisan J M and FernandezLafuente R 2006 Enzyme Microb. Technol. 38(7) 960-966.

[38] Amit A G, Mariuzza R A and Phillips S E V 1986 Science 233 747-753.

[39] Rao S V, Anderson K W and Bachas L G 1998. Mikrochim. Acta 128 127-143.

[40] Sutton, B.J., and D.C. Phillips. 1983. Biochem. Soc. Trans. 11 130-132.

[41] Gering JP, Quaroni L and Chumanov H. 2002 J. Colloid Interface Sci. 252 50-56.

[42] Danczyk R, Krieder B, North A, Webster T, HogenEsch H, Rundell A 2003 Biotechnol. Bioeng. 84(2) 215-223.

[43] Batalla P, Fuentes M, Grazu V, Mateo C, Fernandez-Lafuente R and Guisán JM 2008 Biomacromolecules 9 719-723 